\title{
Infectious disease risk perception among Tunisian students: a case study of Leishmaniasis
}

\author{
Foued Maaoui ${ }^{1}$, Imen Moumni ${ }^{2}$, Lasaad Mouelhi ${ }^{1}$ \\ ${ }^{1}$ ISEFC Bardo, Virtual University of Tunis, Tunisia, ${ }^{2}$ Imen Moumni, Laboratory of Molecular and Cellular Hematology, Pasteur Institute of Tunis, \\ Tunisia \\ Keywords: global health
}

https://doi.org/10.29392/joghr.3.e2019007

\section{Journal of Global Health Reports}

Vol. 3, 2019

\section{Background}

In North Africa, especially in Tunisia, leishmaniasis is a real public health problem with 2000 to 8000 cases per year and average incidence rate $>1 / 100$ in some hyper-endemic villages.

The geographical extension of the three forms of this zoonosis, the high incidence, the exorbitant cost (management, control) and especially the harms: functional, aesthetic, social, psychological are issues that question the promotional role of health education in Tunisian schools. In Tunisia, the introduction of health education in biological programs and textbooks aims at acquiring the knowledge and skills needed to prevent health risks. The present study aims to detect possible failures and to present a path of intervention to innovate preventive measures against infectious diseases.

\section{Methods}

This is a study conducted in two stages: First, a cross-sectional survey, which included 261 Tunisian school students from different educational levels and residents in different regions of the country. Second, a didactic analysis of Tunisian curricula related to infectious diseases prevention.

\section{Results}

All of the results showed that students in general, do not really know this disease, especially with regard to risks, treatments and prevention. The question on the knowledge of the three most common diseases in Tunisia that can be transmitted by contact with animals or insects seems to have been difficult to understand. The fact that a large proportion of school students did not answer the question, and, that another group, mentioned infectious diseases that are absent in Tunisia or not zoonotic, could reveal a lack of knowledge about infectious disease, related to animals. A curriculum analysis of recent Life Sciences textbooks reveals a dominance of the biomedical model. The promotional model is almost absent.

\section{Conclusion}

Deficits noted in terms of knowledge, perceptions and management capabilities of cutaneous leishmaniasis can be explained by the absence of this disease in Tunisian Life Sciences curricula. Currently, empowerment and psychosocial skills development, which are essential to perceive and manage the risks of zoonotic infection, are not among the health educational aims.

The health education participates in the progressive acquisition of knowledge and skills which will allow the pupils to make a responsible choice regarding health. In this perspective, Tunisia accords to the health education a significant place among the missions assigned to the school system. The Tunisian youth being confronted with new problems, new challenges and plagues. Indeed, the propagation of new parasitic and virology infections interrogates the role of school in the prevention and the promotion of health. How to allow a young person today, an adult tomorrow, to make responsible choice? Leishmaniasis is an example of epidemiological challenges faced by young north Africans.

Leishmaniasis is a parasitic disease causing very debilitating skin or visceral diseases, ${ }^{1}$ even fatal if they are not treated. They are due to different parasites of the genus Leishmania, transmitted by the bite of insects commonly called sandflies. Every year, an estimated 2 million new 
cases of leishmaniasis are diagnosed worldwide, and these parasitosis are now considered neglected diseases. ${ }^{2}$

The first cases of cutaneous leishmaniasis in Tunisia, were described in 1884, in Gafsa, by Deperet and Boinet. ${ }^{3}$ Since 1985 , the analysis of observations of patients from all over the territory, has made it possible to individualize 3 distinct noso-geographical forms. These are differentiated by their geographical distribution, their clinico-epidemiological aspect, their causative agent, as well as by their serological profile.

Three forms of cutaneous leishmaniasis are endemic in Tunisia ${ }^{1,3}$ : Sporadic northern LC (LCS), caused by Leishmania infantum, zoonotic LC caused by Leishmania major in the center and south, and chronic LC (LCC) caused by Leishmania tropica (Killicki leishmania syndrome) in the circumscribed homes of the South-East and Center. The LCZ is by far the most common, with an annual incidence of 2000 to 5000 cases for some epidemic years.

The geographical distribution of the LCZ in Tunisia is conditioned $^{1,3}$ by the environmental factors and climatic changes observed in recent years mainly in relation to the mobilization of water resources, agricultural development and urbanization, contributing to an increase in the density of the disease vector and that the epidemiology of these protozoa is evolving. Indeed, it is located more in the center and south of Tunisia.

Sidi Bouzid is a hyper-endemic region ${ }^{3}$ and is therefore the main focus of the disease in the country.

Kairouan and Gafsa are an endemic area where transmission is maintained constant.

Sfax, Gabes, Kebili, Mahdia, Tozeur and Kasserine are areas where transmission is seasonal with low incidence. Tataouine is an area of zoonotic leishmaniasis type "Leishmania Killicki" at low and medium incidence. From 1991, the incidence varies between 20 and 270 per 100,000 inhabitants. $^{3}$

Preventive measures can reduce the risk of infection. ${ }^{1,3}$ Water management and irrigation practices need to be adapted to limit exposure to the disease. Farmers are encouraged to avoid irrigating at night, limiting soil saturation and water loss, and repairing defective equipment. In addition to reducing health risks, these measures help to intensify agricultural production through more efficient irrigation. On the other hand, families are advised to keep pets, manure and garbage away from homes.

Unfortunately, the preventive actions are still limited to the fight against sandflies by repellents, ${ }^{3}$ impregnated mosquito nets, the wearing of clothes covering the maximum surface. So, to the respect of the fundamental rules of the prophylaxis against sandflies. Despite the multitude of research work that is interested in this disease, progress remains insufficient on the therapeutic (Efficacy, complexity, toxicity) or preventive (Zoonosis difficult to control) side.

The cutaneous LC remains for Tunisia a real challenge and this is due in large part to the difficulty of setting up large control programs, very expensive and difficult to implement. ${ }^{3}$ Hence the interest of ecological control actions, conducted by the Ministry of Agriculture and Environment in close collaboration with the Ministry of Health. Better consideration of the didactical determinant and health ed- ucation of the youngest would be strategic to optimize preventive measures.

Indeed, the democratization of health measures in developing countries, through access to healthcare and health promotion closer to young people, allows optimal management of epidemiological risks.

In Tunisia, the introduction of health education in biological programs and textbooks aims at acquiring the knowledge and skills needed to prevent infectious risks. The textbook is a didactic help through which, the society can guarantee the didactic, scientific, educational and professional competence of the teachers. Besides, the influence of textbooks seems even more dominating in developing countries. ${ }^{4}$

The issue of new risks and emerging risks is ubiquitous in the media; students are constantly confronted with it more than by real experience. It thus seems likely that the perception of risks has increased enormously and sometimes in inverse proportion to their quantitative reality.

It should be recalled that "health education covets the acquisition of scientific information, the adoption of good health practices and the development of skills and psychosocial skills, such as self-knowledge, self-esteem, respect for self and others, critical thinking, personal judgment, resistance to pressure (peers, media), and the ability to communicate". 5

It is clear that each infectious disease has its own representations for the students: tuberculosis, hepatitis, leishmaniasis and influenza each carry their own lot of knowledge, explanations, fears, images. Are there a number of common bases for young people to understand the interactions between humans and infectious agents? And could we build an educational strategy on these bases? To answer this question, it was necessary to be able to analyze the profane knowledge of each infectious disease and to confront them with each other.

What is the place of the media and the school in terms of perceptions, attitudes, and behaviors?

Are sociodemographic determinants the only ones to be considered when it comes to prevention and health promotion, as is the case now? Should the role of the school textbook be re-evaluated in the national prevention and health promotion strategy in view of the training of pupils who are actors in their health?

The perceptions, attitudes and behaviors of young Tunisians regarding infectious risks should be evaluated in order to optimize educational strategies. Despite their incidence in Tunisia, leishmaniases are not subject to teachinglearning in Tunisian Life Sciences curricula.

The present study aims to detect possible failures in health education as it is currently conducted in Tunisian school and to present a path of intervention to innovate preventive measures against infectious diseases.

\section{METHODS}

This was a cross-sectional survey, which included 261 Tunisian school students from different educational levels and residents of different regions of the country.

A health barometer elaborated in the form of a questionnaire for school students in the $9^{\text {th }}$ year of preparatory schools and $2^{\text {nd }}, 3^{\text {rd }}$ year (Experimental and Letters section) 
and $4^{\text {th }}$ experimental section of secondary schools. School students were asked on several themes in the term of the perceptions, attitudes and behaviors of different infectious risks, in the form of questions concerning zoonoses, seasonal flu, pneumonia, rhino-pharyngitis, vaccination and hygiene measures. In this work, we were interested in the case of Leishmaniases. It is clear that each infectious disease has its own representations for students: Leishmaniases each carry its own lots of knowledge, explanations, fears, images. This survey aimed to explore the current knowledge, attitudes, beliefs and behaviors of Tunisian school students towards zoonotic risks.

\section{GENESIS OF THE SURVEY}

Our questionnaire was based on KABP-type surveys (Knowledge, Attitude, Behavior and Practice), used by social epidemiological studies to assess the perceptions, attitudes and behaviors of populations with respect to infectious risks in general.

Given the subject of our study, we adapted this tool to explore school population perception for leishmaniasis. In addition, the KVP model (knowledge, values, practices), ${ }^{6}$ which analyzes on the one hand the initial references of the transposition and on the other hand the programs and textbooks, was used to evaluate the achievement of the health education aims, conveyed by Tunisian Life Sciences curricula.

From a theoretical point of view, different approaches have been used to understand how risk perception is constructed. In a schematic way, three approaches are generally distinguished. ${ }^{7-9}$

The first developed by Slovic in 1975 and Fischhoff in $1978^{10,11}$ is a psychometric approach to risk that proposes a cognitive stimulus / personality / response model that is very focused on the individual dimension of risk and the use of risk assessment scales.

The cultural and societal approach to risk put forward by Douglas and Wildawsky in $1982^{12}$ introduces the dimension of the social context and in particular the belonging of individuals to social groups as an explanatory dimension of risk perception.

Finally, the most recent constructivist approach ${ }^{13}$ proposes a theory of social risk amplification that emphasizes the notions of value systems and social imitation to which individuals are subjected.

In this study, the analysis focuses on general issues related to the perception of Leishmaniasis risk and its place among other infectious diseases, the identification of practices perceived to be at risk of contracting this zoonotic disease, preventive behaviors adopted by the school students and their knowledge.

\section{SAMPLING}

The population concerned were Tunisian students aged between 14 to 19 years old, educated in preparatory schools and secondary schools in the North, Center and South of the country. The sample was representative of grade levels; 9 th year preparatory school, 2nd and 3rd year (experimental
Table 1. Structure of the sample obtained in pupils 9th of preparatory school by gender and region of residence, for an age group $(14-16$ years $)(n=100)$

\begin{tabular}{llcc}
\hline & & Numbers & Percentages \\
\hline Total & & 100 & 100 \\
\multirow{3}{*}{ Sex } & Male & 41 & 41 \\
& Female & 59 & 59 \\
\multirow{3}{*}{ Region } & Tunis & 43 & 43 \\
& Ben Arous & 57 & 57 \\
\hline
\end{tabular}

Table 2. Structure of the sample obtained in secondary school students by gender, study specialty, grade level and region of residence for an age group (16-22 years) $(\mathrm{n}=161)$

\begin{tabular}{llcc}
\hline & & Number & Percentages \\
\hline Total & & 161 & 100 \\
Sex & Male & 36 & 22.4 \\
& Female & 125 & 77,6 \\
Study & $2^{\text {nd }}$ Sciences & 19 & 11.8 \\
and & $2^{\text {nd }}$ Letters & 18 & 11.2 \\
School & $3^{\text {rd }}$ Sciences & 25 & 15.5 \\
level & $3^{\text {rd }}$ Letters & 67 & 41.6 \\
& $4^{\text {th }}$ Sciences & 32 & 19.9 \\
& Kef & 30 & 18.6 \\
& Siliana & 26 & 16.1 \\
Region & Kairouan & 23 & 14.3 \\
& Gafsa & 40 & 24.8 \\
& Tataouine & 42 & 26.1 \\
\hline
\end{tabular}

sciences and letters section) and 4 th year experimental sciences section (Table 1 and Table 2).

This sampling takes into account the geographical distribution of Cutaneous Leishmaniasis in Tunisia. We illustrate in Figure 1 and Figure 2 the diversity of Leishmaniasis forms and their distribution in Tunisian territory. Frequencies used in the mapping process are from regional directions of Health and Tunisian Observatory of New and Emerging Diseases.

For feasibility and didactical reasons, sampling was limited to five school levels and seven regions. Our goal is to check the abilities of young Tunisians to perceive and manage Leishmaniasis then to correlate possible deficits with health education model dominant in Tunisian curricula.

\section{CROSSOVER VARIABLES}

The main variables used to characterize the knowledge, beliefs, attitudes and behaviors of the students surveyed are socio-demographic and didactic variables (gender, region of residence, study specialty and grade level, etc.). 


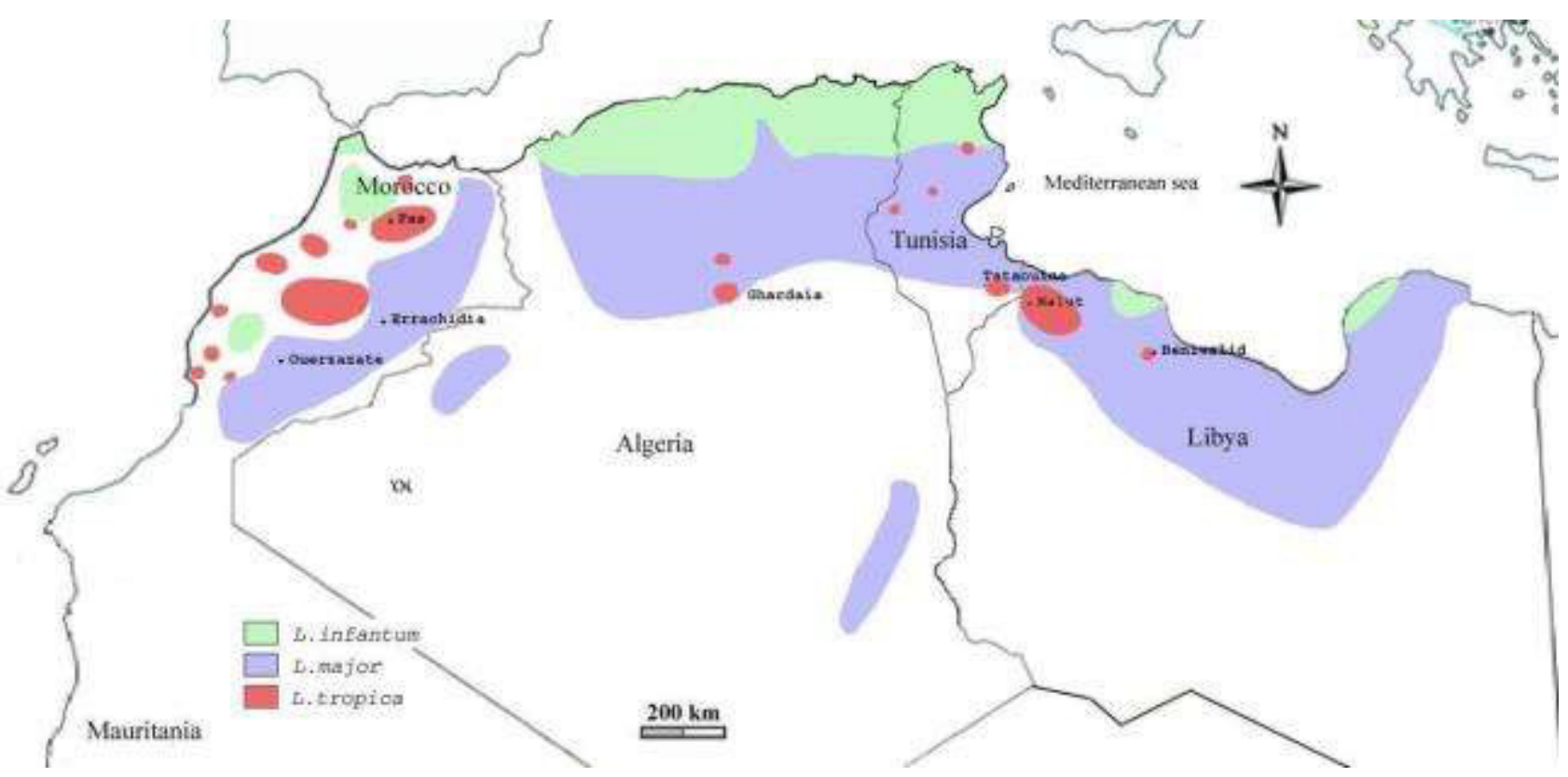

Figure 1. Cutaneous Leishmaniasis in North Africa (Aoun, 2018)

\section{ETHICS}

Ethical approval for the study was obtained at the Comité d'Ethique Bio-Médicale (CEBM) of the Pasteur Institute of Tunis under the reference 2019/3 / E / UVT ISEFC / V1.

\section{RESULTS}

\section{PERCEPTIONS, ATTITUDES AND BEHAVIORS OF SCHOOL STUDENTS}

Leishmaniasis was the penultimate position in the classification of infectious diseases feared by secondary school students questioned (2.6\%) (Figure 3), the same for preparatory school (1\%). It was less and less dreaded when going from one level of education to the next, falling from (5.9\%) to $(0 \%)$ for the scientific levels and from $(5.6 \%)$ to $(1.5 \%)$ for the arts levels. In fact, it concerned students in the south of Tunisia more than those in the north $(7.5 \%$ vs. $4.2 \%$, $P<0.05)$.

Little or no fear, only $33 \%$ of secondary school students surveyed knew that the disease is parasitic (Figure 4). On the other hand, regarding their perceptions of the most dangerous modes of transmission, the attention of the pupils generally focused on the blood and the sexual relations as the most dangerous mode of transmission (Figure 5).

Differences were noticed as the scientific levels showed a more increased sensitivity to the mode of transmission by blood (79.6\% vs. 57.5\%), sexual intercourse (60.8\% vs. $34.1 \%$ ), food (30.5\% vs. $16.5 \%)$, the environment $(21.1 \%$ vs. $10.3 \%$ ) and lower sensitivity compared to arts students to modes of transmission by; animals (15\% vs. $0 \%$ ), cough (33.1\% vs. $4 \%$ ), saliva ( $8.7 \%$ vs. $4 \%$ ).

We explored risk perception and knowledge about the disease: "whether it is or is not a health problem in Tunisia?", "the risk of contamination in 2017? ", "risk fac- tors (mode of transmission)?", "whether there is effective treatment?".

We focused our attention on didactical determinants (School level/Study specialty/Section).

\section{LEISHMANIASIS IS OR NOT A HEALTH PROBLEM IN TUNISIA?}

$47 \%$ of the 261 school students questioned were convinced that leishmaniasis is an important health problem for the Tunisian population: $10 \%$ were "absolutely" for this opinion and 37\% were "rather", 23\% were not able to answer the question (Figure 6).

Nevertheless, this consideration decreased from one level of education to the next, whatever the study specialty, so it fell by half for scientific classes (10.5\% to $4 \%$ ) and (11.1\% to $7.5 \%)$. \%) for arts classes (Figure 7).

\section{PERCEPTION OF THE RISK CONTAMINATION BY LEISHMANIASIS IN 2017?}

To the question asked «In 2017, what do you think is the risk of being contaminated by leishmaniasis»; only (11\%) of the students surveyed thought that the risk is "Important", (35\%) consider it "Medium", close to (27\% and 7\%) evaluate the risk "Low but real" and "Almost zero" respectively. "(20\%) of the school students did not have an answer to this question (Figure 8).

\section{LEISHMANIASIS: KNOWLEDGE ABOUT RISK FACTORS?}

The risks of contracting leishmaniasis by animal contact (insect bite) were moderately considered: (52.8\%) of students seemed to be aware of this risk, (22.4\%) did not think so and $(24,8 \%)$ did not have an answer to this question. Note that the same students questioned, falsely responded positively to the modes of transmission by the; cough 


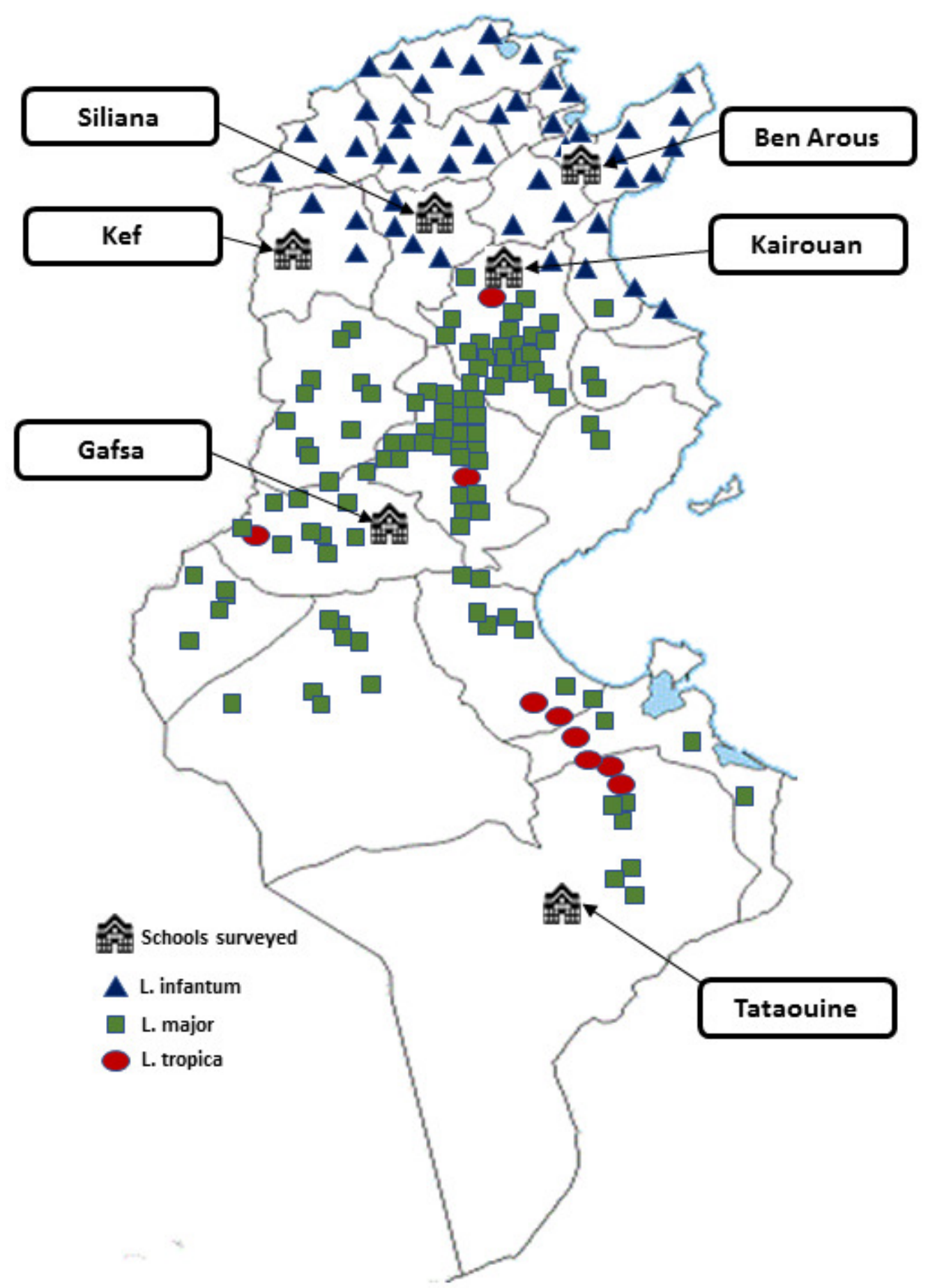

Figure 2. Cutaneous leishmaniasis in Tunisia. 


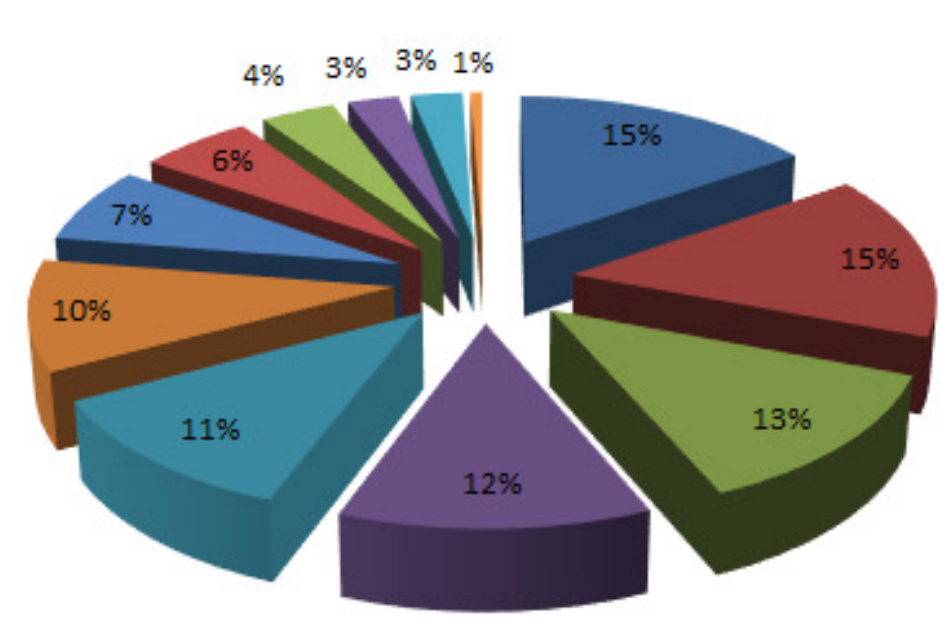

\author{
Nothing \\ Hepatitis \\ - Tuberculosis \\ nydatid cyst \\ - Influenza \\ - Salmone llosis \\ - Pneumonia \\ Bronchiolitis \\ Meningit is \\ nastroenteritis \\ Leishmaniasis \\ nisteriosis
}

Figure 3. Infectious diseases most feared by secondary school students.

Viral Bacterial Darasitic No answer

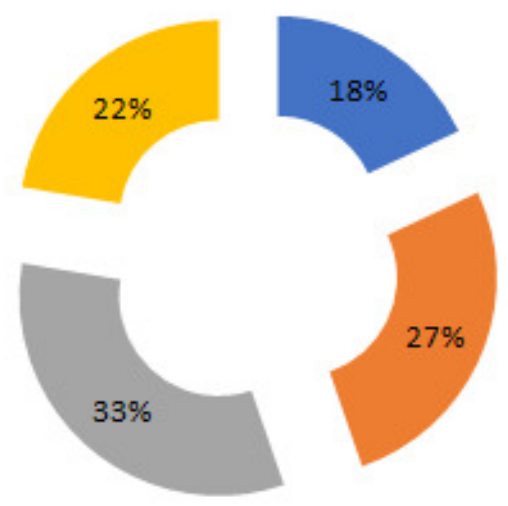

Figure 4. Knowledge about leishmaniasis/Agent responsible.

(23\%), sexual route $(19.3 \%)$, skin $(37.3 \%)$, food route (29.8\%) (Figure 9).

\section{LEISHMANIASIS: EXISTENCE OF EFFECTIVE TREATMENT?}

(26\%) reported that there is effective treatment for leishmaniasis; (12\%) thought the opposite and more than half (62\%) had no idea (Figure 10 and Figure 11).

All of these results: non-response rate and high proportion of false answers showed some confusion, as well as a lack of real knowledge of these diseases, including risks, modes of transmission, treatment and prevention.

\section{DISCUSSION}

The different theoretical approaches to risk perception can be used to interpret the results of this survey. The subjective and emotional dimension of risk is superimposed on other dimensions such as belonging to social groups and anchoring in specific value systems.

The results show that the perception of leishmaniasis by school students depends on geographical proximity, gender, media coverage and didactic variables (School level: Study specialty/Section).

All the factors coexist objectively and interact with the subjectivity of each individual. Convergence is first of all a perception either spontaneous, is oriented towards normalism under pressure from peers, family and the media. The risk of an epidemic of fear (panic phenomenon) is therefore significant. The welfare state and the health authorities would be the only recourse, dictating standards of good health and prescribing hygiene measures and adequate behavior in accordance with epidemiological knowledge. Verticality (health professionals / patient) is required. The feeling of fear is the only one implemented in the control of decision-making. It can also be reasoned, when personal qualifications take precedence over social and sometimes sanitary conformism. The positivism of a statistical knowledge not always accounting for the originality of the individuals, microbial dynamics and the variation of the contexts. Hence the complexity of the infectious risks, evolves towards more relativism. The emancipation and empowerment of the students in the face of infectious diseases is reinforced by the development of his psychosocial 


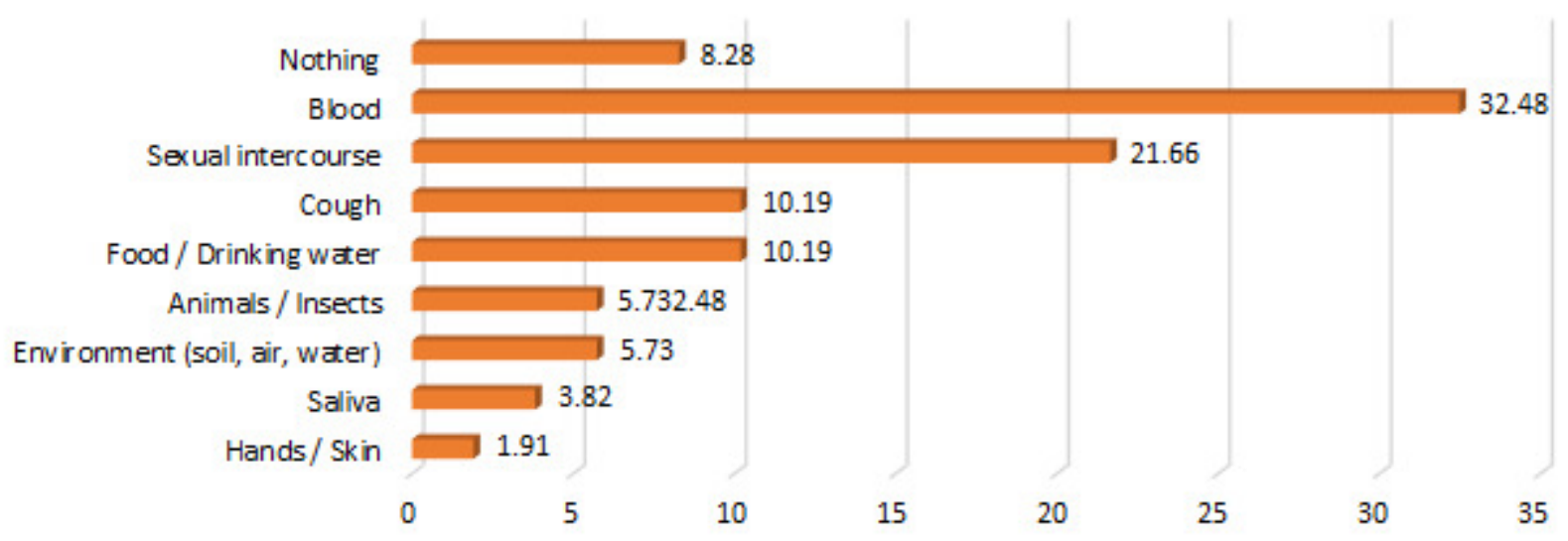

Figure 5. Infectious diseases perception/The most feared transmission modes.

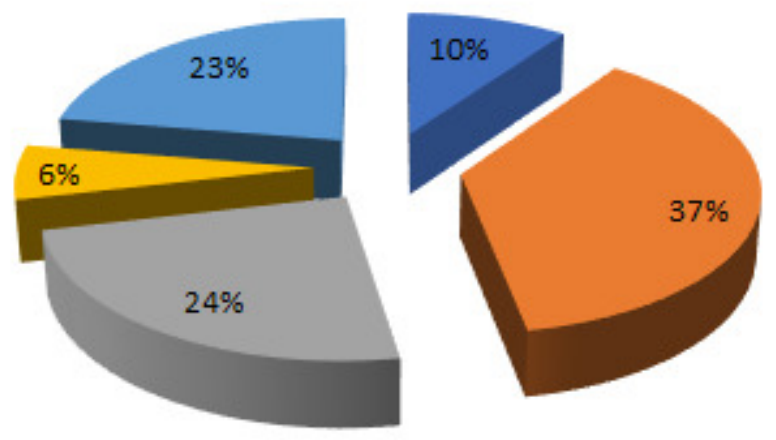

- Yes, absolutely

- Yes, rather

Not rather

Not at all

No answer

Figure 6. Leishmaniasis is a health problem in Tunisia?

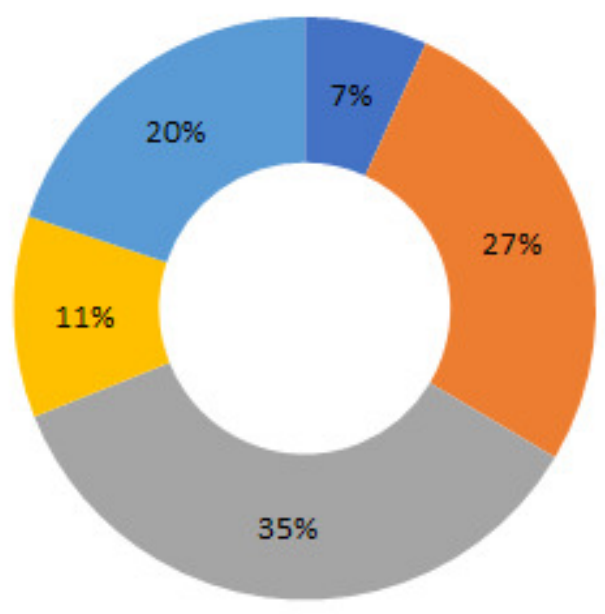

\author{
Almost nothing \\ - Low but real \\ medium \\ Important \\ No answer
}

Figure 8. Contamination risk perception by leishmaniasis in 2017. 


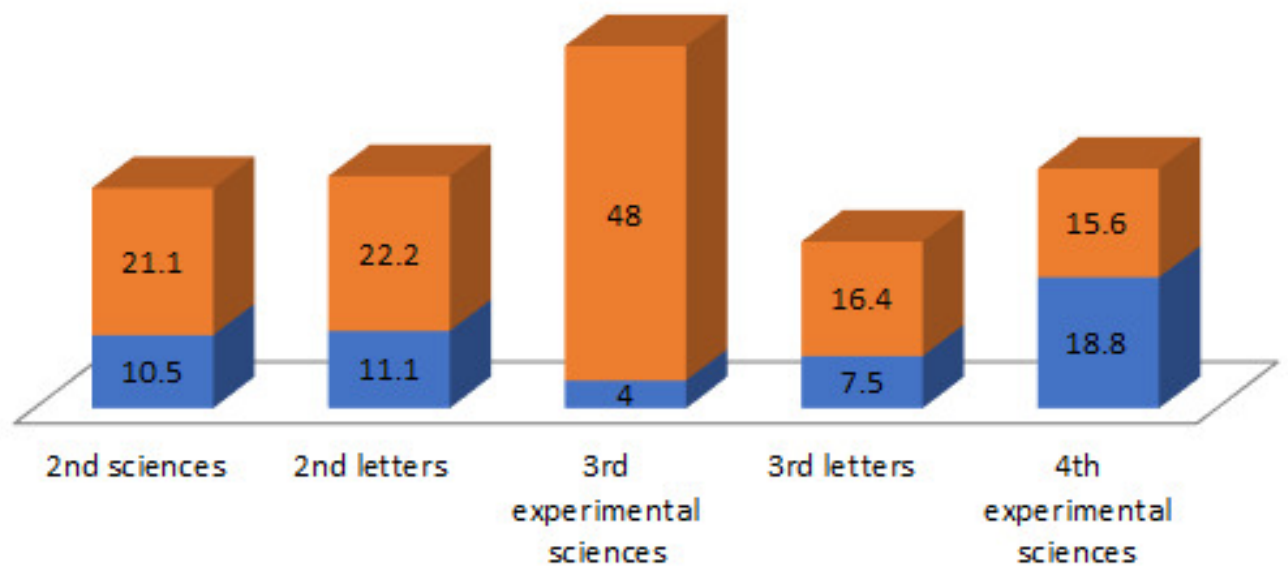

Figure 7. Leishmaniasis is a health problem in Tunisia? Responses by grade level.

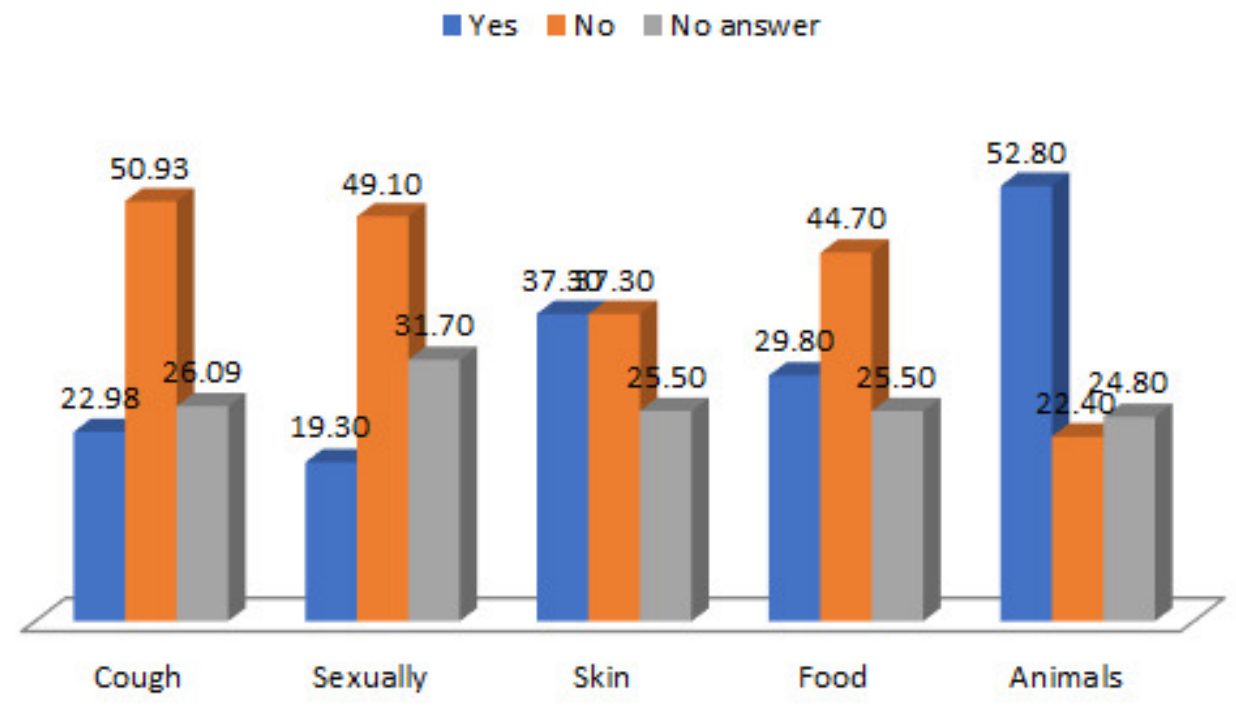

Figure 9. Knowledge about leishmaniasis/Transmission mode.

skills. We believe that this is a condition for the acquisition of reasoned perception abilities (qualification and quantification of infectious risk) and management (choice and planning of adequate preventive strategies) (Figure 12).

The relation (patient / doctor) is more interactive so they become partners in the therapeutic path.

In the first case the spontaneous perception is followed by a hazardous or intuitive management of infectious risks.

In the second case the reasoned perception is then relayed by an optimal thoughtful management. The regulation and the implementation of the strategies of prevention (search of information, measures of avoidance, personal hygiene, consultation of doctor, homeopathy, protection of others, ...) is not made only by fear but especially following to a reflection evaluating the consequences of the decisions to be taken. The knowledge acquired is mobilized in everyday life.

Thus, actions such as: avoid night irrigation, move manure away from dwellings, purge stagnant water, installation of septic tanks, wear impregnated masks, alert the health authorities in the event of an epidemic, be aware of climate issues, to know the importance of rational management of water and soil resources, protect the environment individually and collectively, medical and therapeutic autonomy (public/private vaccination; taking antibiotics; consultation of doctor, nurse, pharmacist, homeopath, or marabou). 


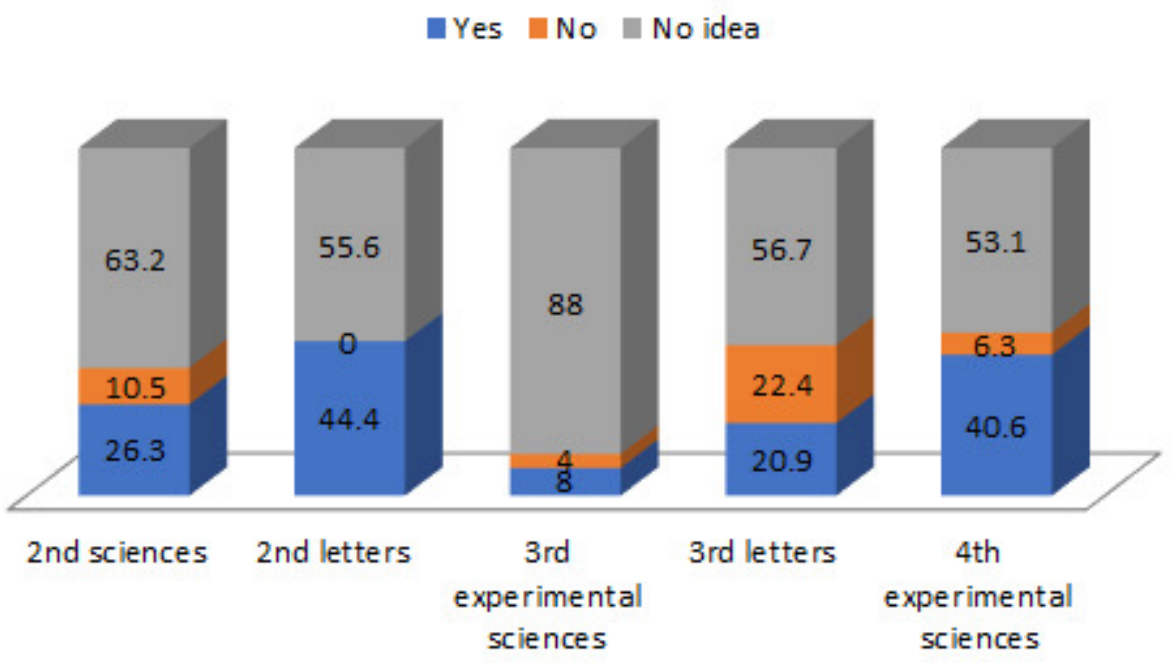

Figure 11. Existence of effective treatment / responses by grade level.

Yes No No idea

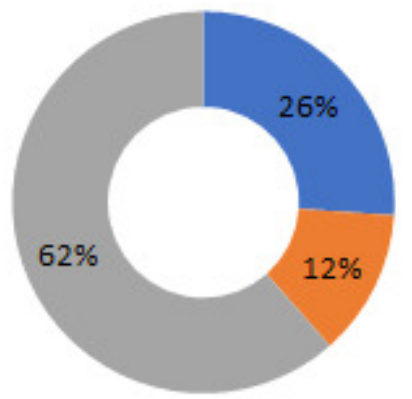

Figure 10. Existence of effective treatment.

Then the evolution of a passive student (who suffers) to a reflexive practitioner (who acts) is dependent on his empowerment (empowerment or emancipation). It is the role of promotion to health through school education through life sciences.

The results of the survey conducted among Tunisian preparatory and secondary school students show that the impact of the content allocated to the prevention of infectious diseases is real (the perception of risk is dependent on didactic variables). However, in our case health education does not allow to develop a reasoned perception of the infectious risk and consequently optimal management of infectious diseases.

The knowledge acquired is punctual and the perception of risk in some cases is inversely proportional to the transition from one grade level to the next, it is regressive.

Indeed, school students are relatively unable to judge the presence and dangerousness of certain infectious diseases as leishmaniasis, mobilize acquired knowledge specific to each of the diseases mentioned, apprehend the infectious risks in the different situations proposed, adopt appropriate preventive measures for each infectious risk, estimate the dangerousness of certain risky behaviors, have positive attitudes towards one self, one's family and in the community.

This survey focuses on the didactic dimension. In Tunisia, the health education of the youngest is conveyed mainly by Life Sciences textbooks and the common ground along the school path in preparatory school then specific according to the orientation of the student towards scientific or literary sections. Themes and chapters studying concepts in relation to infectious diseases differ according to the specialty of school study (section and grade level of the student).

We are interested in studying the impact of its variables on students' perception of infectious risks, their modes of transmission and the means of prevention to be adopted and their evolutions by going from one grade level to the next. Media coverage and social amplification for certain infectious diseases also play a role in the construction of risk perception among students.

\section{THE SOCIAL DIMENSION OF RISK PERCEPTION}

The survey confirms that perception of risk has a strong social dimension and is influenced by certain sociodemographic variables and in particular gender.

Female students generally have a more acute perception of risk. They are more likely to perceive the possibility of contracting an infectious disease in everyday situations ( $24.8 \%$ vs. $8.6 \%, P<0.05)$.

Note the large number of school students expressing no fear of infectious diseases, even more so for male school students than for female $(22.9 \%$ vs. $13.2 \%, P<0.05)$. Assumptions about the social roles of future men and women in society can be explored to explain these differences in risk perceptions among students.

It is especially possible that male students have tended to minimize their statements: to feel fears is not necessarily 
Empowerment/Auto-regulation

PotentialInfectious Risk

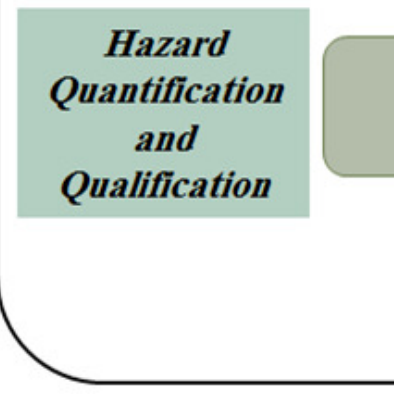

Social, economical, political, environnemental constraints Media coverage: Amplification or Reduction Health Education: Didactic and Pedagogical choices

Figure 12. Infectious risk perception and management process.

consistent with the images traditionally associated with manhood.

Female school students tend to adopt more preventive behaviors and therefore seem more aware of serious illnesses. They are also more worried about the risks that may affect their loved ones.

The hypotheses put forward to explain this differentiated perception by sex are both biological and social. Indeed, these future women are more concerned with human health because they have the biological capacity to give life, then the social function to maintain it. The social role assigned to women assigns them responsibility for the family sphere and all that relates to it, including food, care for children and the elderly. Women often feel confident about family health and are therefore more aware of infectious diseases.

Beyond gender, socio-geographical variables such as place of residence influence the perception of the risk of infection. Recall that the incidence of leishmaniasis is high in the center and south of the country compared to the north. School students in southern Tunisia report significantly higher fear of leishmaniasis than school students in the north.

\section{THE DIDACTIC DIMENSION OF RISK PERCEPTION}

In addition to the social dimension, the survey confirms above all that risk perception has a strong didactic dimension, as well as belonging to a scientific or literary section, as well as the transition from one school level of to the next, are variables that influence perception of the risk of infection by the school student. An inter and intra-specific analysis taking into account didactic variables shows a significant difference in the fear of infectious diseases, according to the study specialty and the school level. Recall that, the analysis of Life Science curricula, ${ }^{5,14-16}$ reveals that the model of health education adopted in textbooks is the biomedical model rather centered on the transmission of information (responsible agent, symptoms, mode of transmis- sion), concerning some examples of infectious diseases, and injunctions (enumeration of hygiene measures).

The analysis of prescribed and potential curricula also shows the vertical discontinuity that characterizes the educational path of Tunisian school students.In fact, infectious risks are treated differently in life science textbooks. Thus, the examples of infectious diseases, proposed in the activities, vary according to the section and the school level.

The disparity of perception, found between the scientific and literary section, is mainly explained by the differences in the contents of the textbooks of life sciences. Despite the incidence of leishmaniasis in Tunisia, the disease is absent in textbooks. But besides, vertical "disparity", we note a regression of the perception of the infectious risk by passing from one school level to the next in the same specialty of study ( $2^{\text {nd }}$ Letters $/ 3^{\text {rd }}$ Letters) and ( $2^{\text {nd }}$ Sciences $/$ $3^{\text {rd }}$ Experimental Sciences), which discusses the limitations of the dominant biomedical model and the informative-injunctive educational style in the life sciences textbooks. The knowledge produced is obviously punctual. The content allocated to the prevention of infectious diseases does not allow development of a culture of health and critical thinking in order to identify false information, make everyone an autonomous and responsible citizen, form young people aware of public health issues.

\section{THE EMOTIONAL DIMENSION OF THE PERCEIVED RISK}

Understanding the process of constructing the school student's perception of risk is complex. First, risk perception refers both to notions of disease severity and incidence. It then involves biological, social and didactic factors, as we have just seen.

Beyond this objective dimension of risk, other less rational elements can participate in the construction of perceptions; for some authors, emotions and feelings are the essential dimension. ${ }^{17}$ Thus, ${ }^{9}$ distinguishes the observed risk produced by the epidemiology of the perceived risk. The 
perceived risk can be apprehended according to a psychosocial approach as "a subjective judgment on a risk in which a quantified estimate is mixed with emotional reactions in relation to the nature of the risk and the acceptability for oneself and society".

Thus, the survey shows that the perception of risk in some cases may be inversely proportional to the exposure of the person to the same risk. Students living in rural areas say they fear more chronic infectious diseases (hepatitis, AIDS, etc.), while it is the highly urbanized regions of Tunisia that have the highest rates of AIDS prevalence. A quantified estimation of the risk, the emotional reactions and the acceptability of these risks for each of these populations thus make it possible to understand why some risks will be amplified by certain population groups while they are objectively little exposed and, conversely other risks will be minimized in case of high exposure.

\section{THE STUDY LIMITATIONS}

For feasibility and didactical reasons, sampling was limited to five school levels and seven regions in the North, Center and South of Tunisia. Our goal is to check the abilities of young Tunisians to perceive and manage Leishmaniasis then to correlate possible deficits with health education model dominant in Tunisian curricula.

Although this zoonosis is common to North African countries, we are aware that the political, socio-economic, media and didactic contexts are not the same. A comparative analysis of the perceptions, attitudes and behaviors of the Algerian and Moroccan school populations would be interesting to develop common health promotional strategies.

\section{CONCLUSIONS}

We believe that the Tunisian curricula is far from promoting the development of psychosocial skills and empowerment essential: the reasoned perception (qualitative and quantitative assessment of the danger) and optimal management of infectious risk in often unprecedented and complex situations.

Leishmaniasis prevention depends on an awareness of policy makers and the active participation of the population. Health education being one of the levers of health promotion and social equity that integrates care, population health and sustainable development.

In the present case, the achievement of health education preventive aims in the face of infectious diseases would depend on development of a clear competency framework for health education, evolution of the current biomedical model towards the promotional model, adherence to a participative style of education, update of the infectious examples studied to current and future epidemiological challenges (Zoonotic diseases, Hepatitis, Super-bacteria), content update and integration of the concept of human microbiota, contextualization of the studied infectious examples to the reference social practices, reduction of the vertical disparity between the different specialty and sections, consider a multidisciplinary health education, promote project and investigation pedagogies while involving families, civil society and health professionals, sensitization of educational actors to the concepts and aims of health education and reconcile the concepts of health education with those of the environment (environmental impacts and health issues).

\section{ACKNOWLEDGEMENTS}

This study is the result of a collective work. We are grateful to the school students and teachers who participated in the dissemination and collection of the mentioned data. The collaboration with researchers from the Pasteur Institute of Tunis was a source of inspiration and essential expertise.

\section{FUNDING}

None.

\section{COMPETING INTERESTS}

The authors completed the Unified Competing Interest form at http://www.icmje.org/coi_disclosure.pdf (available upon request from the corresponding author), and declare no conflicts of interest.

\section{CORRESPONDENCE TO:}

\section{Foued MAAOUI}

Researcher in Education Sciences

Laboratory of Molecular and Cellular Hematology

Pasteur Institute of Tunis

1002 Tunis

El Belvedere

Tunisia

maaoui_foued@hotmail.com 


\section{REFERENCES}

1. Aoun K. La leishmaniose cutanée en Tunisie: épidémiologie, stratégies de prise en charge et de contrôle. Nantes. Accessed June 14, 2018. http://ww w.infectiologie.com/UserFiles/File/ini/2018/com/ini20 18-lc-tun-aoun.pdf

2. World Health Organization. Leishmaniasis. Published 2018. Accessed August 12, 2018. http://ww w.who.int/news-room/fact-sheets/detail/leishmaniasi $\underline{\mathrm{S}}$

3. Mhamdi Z. Les Leishmanioses Cutanées En Tunisie. University of Bordeaux; 2013.

4. Khzami S, Agorram B, Selmaoui S, Clement P, El Hage F, Bernard S. L 'éducation à la santé: analyse comparative des manuels scolaires de biologie de 3 pays méditerranéens. Education et Formation. 2010;292:57-67.

5. Saab O. L'éducation à la santé en milieu scolaire au Liban: d'une approche analytique biomédicale vers une perspective écologique biopsychosociale. Etude curriculum, des manuels scolaires libanais de Sciences de la Vie. Published online 2013.

6. Clément P. Conceptions, représentations sociales et modèle KVP. HAL. 2014;16:55-70.

7. Vergriette B. Perception du risque et participation $d u$ public. Afsset; 2006.

8. Kermisch C. Vers une définition multidimensionnelle du risque. Vertigo. 2012;12:2. do i:10.4000/vertigo. 12214

9. Setbon M. Perception et gestion du risque. In: Académie des Sciences. L'épidémiologie humaine: conditions de son développement en France et rôle des mathématiques. Rapport Science et Technologie. EDP Sciences; 2006:123-136.
10. Slovic P. Perception of Risk. Science. 1987;236(4799):280-285. doi:10.1126/science. 356350 $\underline{7}$

11. Fischhoff B, Slovic P, Lichtenstein S, Read S, Combs B. How safe is safe enough? a psychometric study of attitudes towards technological risks and benefits. Policy Sci. 1978;9(2):127-152. doi:10.1007/bf $\underline{00143739}$

12. Park S. Risk and culture: An essay on the selection of technical and environmental dangers. International Review of Public Administration. 2010;15:81-82. doi:1 $\underline{0.1080 / 12294659.2010 .10805168}$

13. Kasperson RE, Kasperson JX. The social amplification and attenuation of risk. Ann Am Acad Pol Soc Sci. 1996;545:95-105. doi:10.1177/0002716296 $\underline{545001010}$

14. Lange J, Victor P. Didactic "curriculaire" and 'education with... health, environment and with the sustainable development': which questions, which marks? Didaskalia. 2006;28:85-100.

15. Lange VP, Janner M. L'éducation au développement durable: contexte, enjeux et missions éducatives. University of Geneva; 2010.

16. Khzami S, Agorram B, Selmaoui S, Clement P, Hage FE, Bernard S. L'éducation à la santé : analyse comparative des manuels scolaires de biologie de 3 pays méditerranéens. Education et Formation. 2010;e-292:57-67.

17. Loewenstein GF, Weber EU, Hsee CK, Welch N. Risk as feelings. Psychol Bull. 2001;127(2):267-286. do i:10.1037/0033-2909.127.2.267 